\title{
O equilíbrio da inflação e os efeitos sobre a economia brasileira
}

\author{
Luciano Nakabashi* \\ Marcelo Luiz Curado **
}

RESUMO - A atual conjuntura da economia aponta que estamos passando pelo período de crescimento mais promissor desde a crise da dívida externa, no começo dos anos 80 . No entanto, a elevação da taxa de juros para controlar a inflação acaba por gerar um círculo vicioso de baixo crescimento. É preciso pensar nos efeitos do aumento dos juros não somente no curto prazo para que o país possa sair do processo de crescimento stop and go que caracteriza o ritmo de seu crescimento desde o início da década de 80.

Palavras-chave: Taxa de juros. Crescimento econômico. Inflação.

\section{INTRODUÇÃO}

A economia brasileira apresentou uma taxa acumulada trienal de crescimento igual a 13,1\% entre 2005-07. No comparativo do primeiro trimestre de 2008 com o mesmo período de 2007, o PIB a preços de mercado apresentou elevação de 5,8\%, enquanto que o valor adicionado a preços básicos apresentou um aumento de 5,5\%, segundo os dados do IBGE (Informativo de Junho de 2008).

Considerando que ainda há expectativas de que a economia brasileira continue a apresentar taxas de crescimento razoavelmente elevadas em 2008 e 2009, pode-se dizer que estamos passando pelo período de crescimento mais promissor desde a crise da dívida externa, no começo dos anos 80 .

A expansão atual deve-se, principalmente, ao crescimento do crédito ao consumo e ao crescimento das exportações, configurando assim um ciclo expansionista puxado pela demanda interna e externa, com melhora das contas externas. Adicionalmente, a elevação da demanda externa melhorou a situação das contas externas da economia brasileira com impactos positivos sobre a manutenção do seu crescimento no médio prazo, além do efeito positivo sobre as expectativas dos agentes.

Não é por acaso que o saldo na conta de investimento estrangeiro direto (IED) sofreu uma significativa elevação a partir de 2004 que ocorreu um crescimento vertiginoso de

\footnotetext{
* Doutor em Economia pelo Cedeplar/UFMG. Coordenador do boletim de Economia \& Tecnologia e professor do departamento de economia (DEPECON-UFPR). Endereço eletrônico: luciano.nakabashi@ufpr.br

** Doutor em Economia pela UNICAMP. Professor e chefe do departamento do curso de Ciências Econômicas da UFPR Endereço Eletrônico: mcurado@ufpr.br.
} 
capitais estrangeiros para investimento em títulos públicos, em 2007, de acordo com dados do boletim do Banco Central do Brasil. Isso sem mencionar o aumento significativo do IBOVESPA desde o início de 2003, passando de 11.602 pontos em 02/01/2003 para 72.592 em 30/05/2008, de acordo com dados da BOVESPA.

No entanto, a economia mostra sinais de perda de fôlego. Essa perda de dinamismo é, em grande medida, conseqüências de medidas tomadas pelos nossos gestores de política econômica. Um bom exemplo é que após perder a liderança no ranking dos juros para a Turquia, em julho de 2007, o Brasil voltou ao primeiro lugar, em 2008. Com as expectativas de elevações adicionais dos juros, o país manterá essa posição indesejada por alguns anos.

Por fim, outro aspecto que merece ser analisado é que embora esta política de elevação da taxa de juros deva reduzir a inflação através de seu efeito de contração da demanda, a fonte central do processo inflacionário brasileiro parece encontrar-se nos efeitos adversos do choque do petróleo e da atual inflação, fenômenos mundiais contra os quais a política monetária local nada pode fazer.

\section{EFEITOS DOS JUROS}

A manutenção dos juros em patamares elevados tem sido um dos grandes entraves ao crescimento da economia brasileira, pois essa é uma variável de grande relevância sobre o crescimento econômico devido aos seus efeitos sobre os níveis de consumo, investimento, taxa de câmbio e dívida pública, além das expectativas.

\subsection{CONSUMO}

O recente aumento do consumo das famílias teve como principais motores o aumento do crédito (juntamente com a redução da taxa de juros) e da renda, além da melhora das expectativas dos agentes em relação ao futuro da economia brasileira.

Pelo Gráfico 1, pode-se notar o expressivo crescimento das operações de crédito ao setores público e privado com recursos livres. Em meados de 2000, a proporção dessas operações em relação ao PIB era de 14,34\%, passando para 25,76\% em abril de 2008. Nota-se ainda, pelos dados apresentados no mesmo gráfico, que a expansão se deu, de fato, a partir do final de 2004. 
GRÁFICO 1 - OPERAÇÕES DE CRÉDITO AOS SETORES PÚBLICO E PRIVADO - RECURSOS LIVRES - (\% PIB)
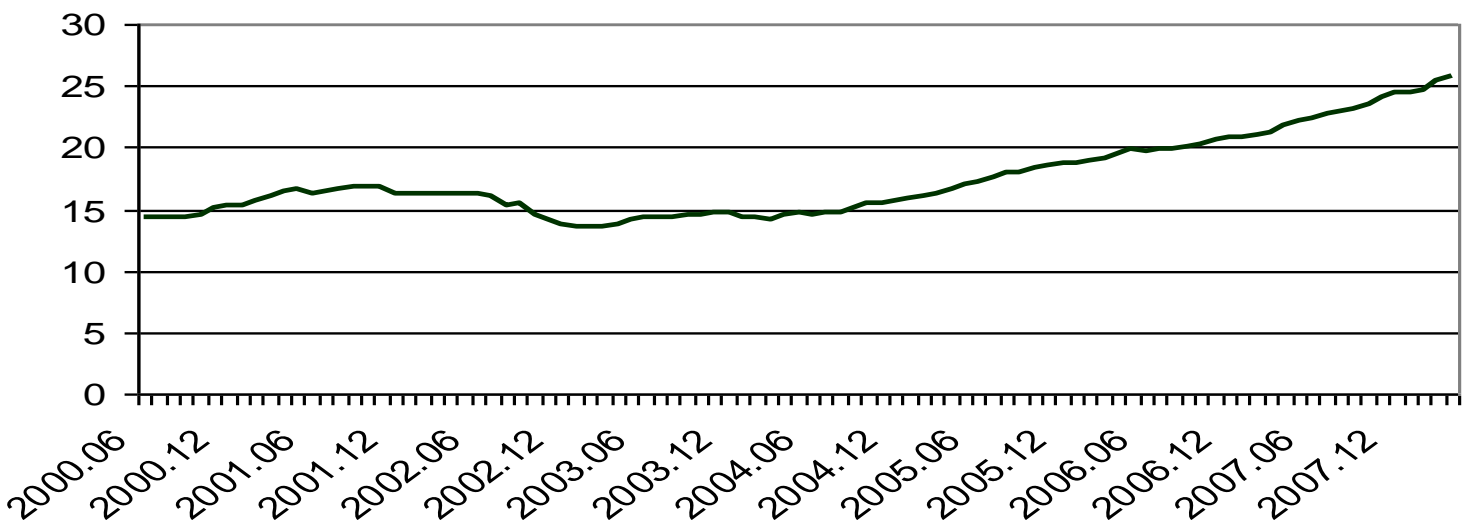

_ Operações de crédito aos setores público e privado - recursos livres - (\% PIB)

FONTE: Elaboração própria a partir de dados do Boletim do Banco Central do Brasil.

Pelo Gráfico 2 fica evidente a queda da taxa de juros das operações de crédito aos setores público e privado. A redução dos juros ocorreu tanto para pessoa física quanto para pessoa jurídica passando de $76,7 \%$ e $40,9 \%$, em junho de 2000 , para $47,7 \%$ e $26,3 \%$, em abril de 2008, respectivamente.

GRÁFICO 2 - TAXA DE JUROS DAS OPERAÇÕES DE CRÉDITO AOS SETORES PÚBLICO E PRIVADO COM RECURSOS LIVRES - PESSOA FÍSICA E PESSOA JURÍDICA (\% A.A.)

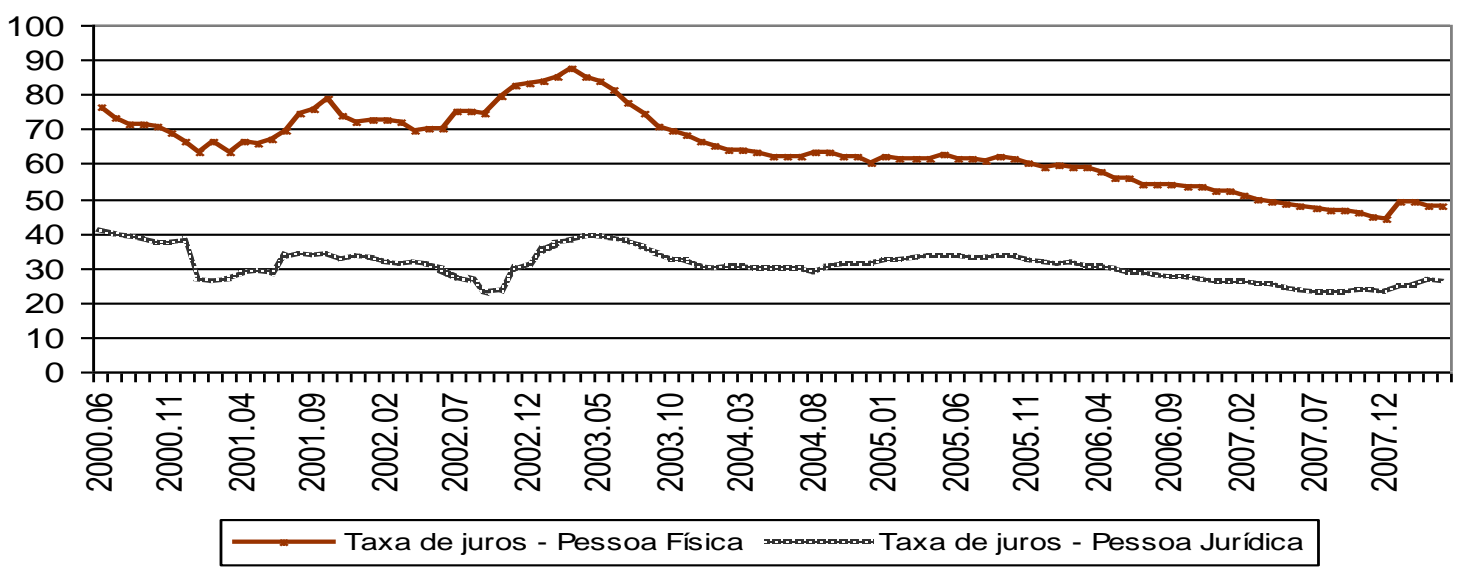

FONTE: Elaboração própria a partir de dados do Boletim do Banco Central do Brasil.

Além da queda da taxa de juros, ocorreu uma elevação do prazo médio das operações de crédito aos setores público e privado com recursos livres, como podemos ver pelo Gráfico 3. Ou seja, essa extensão é outro indicativo das melhores condições de financiamento para as pessoas físicas e jurídicas.

O prazo médio dessas operações aumentou de 369 dias e 211 dias, em junho de 2000, para 457 dias e 298 dias, em abril de 2008, para pessoas físicas e jurídicas, 
respectivamente. Considerando que houve uma queda do prazo até 2004, a melhora, a partir desse ano, foi significativa.
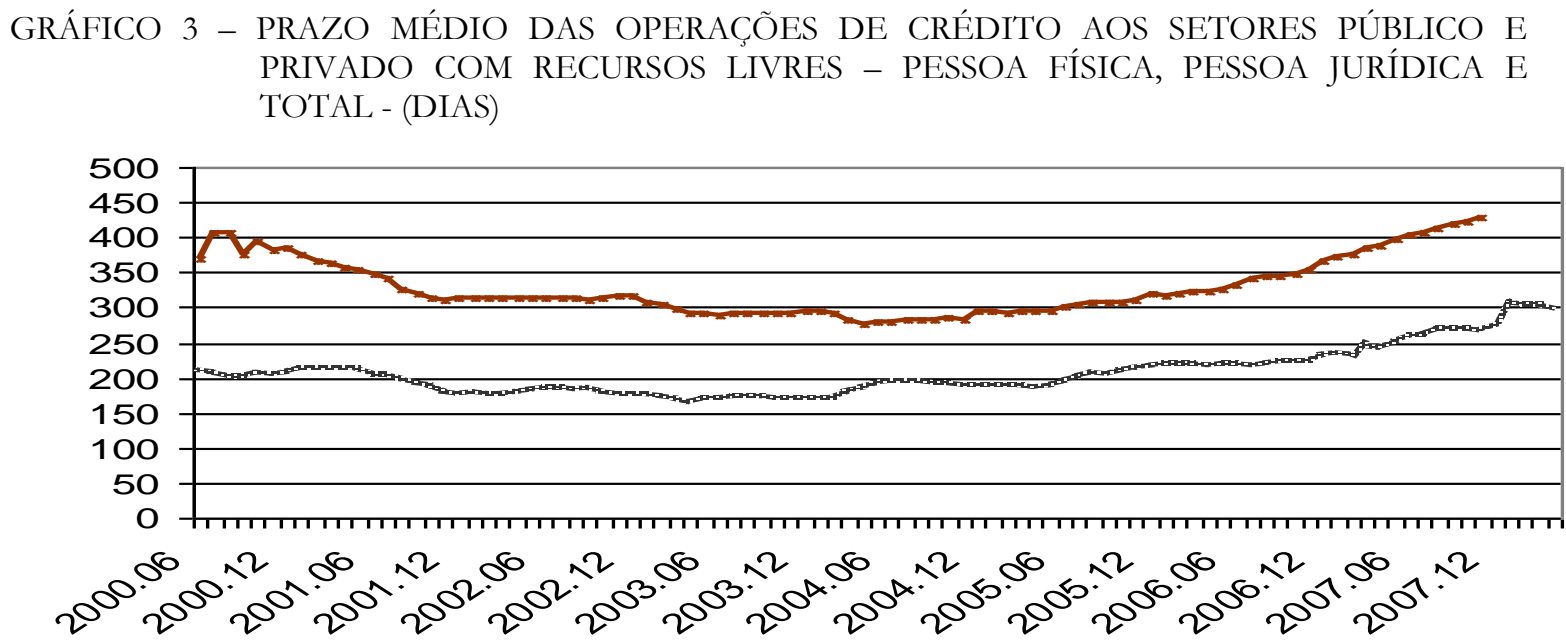

Prazo Médio - Pessoa Física - Dias Prazo Médio - Pessoa Jurídica - Dias

FONTE: Boletim do Banco Central do Brasil.

Uma das conseqüências da melhora nas condições de financiamento e do aumento de renda das pessoas físicas e jurídicas é a queda na taxa de inadimplência dos agentes, como se pode verificar no Gráfico 4.

O próprio processo da queda de inadimplência gera um estímulo para que novos créditos sejam concedidos, gerando um circulo virtuoso de aumento do crédito e da demanda por bens de consumo duráveis e investimentos.

GRÁFICO 4 - TAXA DE INADIMPLÊNCIA OPERAÇÕES DE CRÉDITO AOS SETORES PÚBLICO E PRIVADO COM RECURSOS LIVRES PESSOA FÍSICA, PESSOA JURÍDICA E TOTAL ( $\%)$

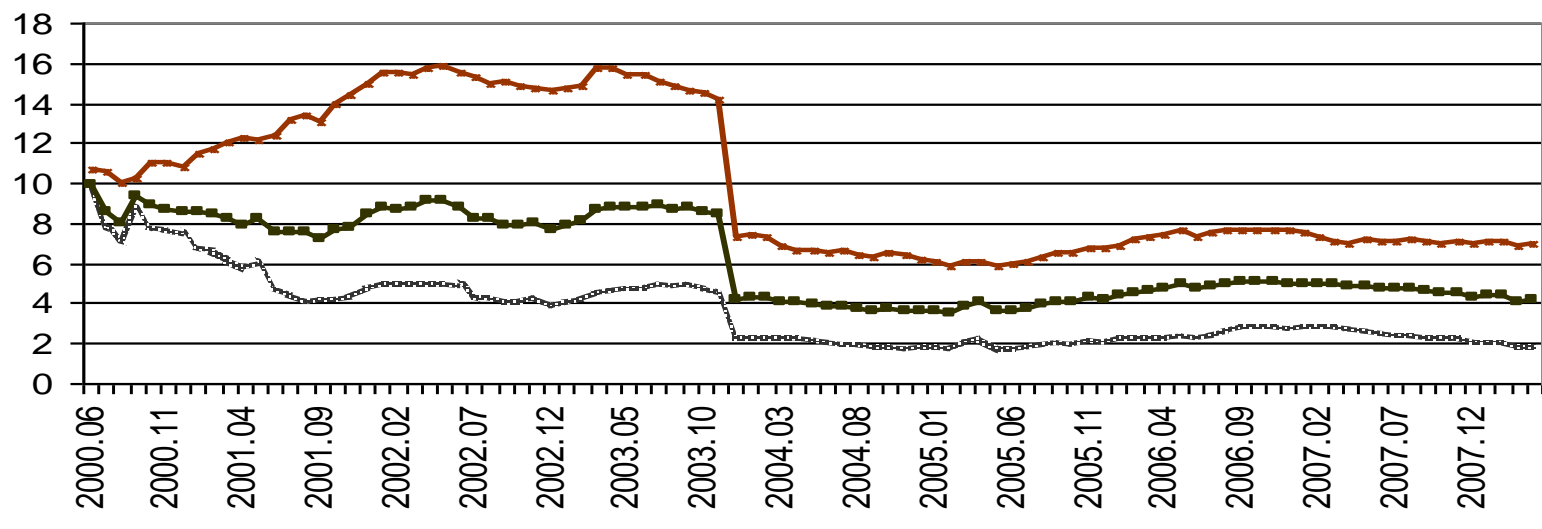

FONTE: Elaboração própria a partir de dados do Boletim do Banco Central do Brasil.
FOnciancia - Pessoa Física

O problema da elevação da taxa básica de juros da economia (Selic) é seu impacto sobre as demais taxas de juros da economia, com efeito na geração de um processo inverso, 
ou seja, redução da demanda interna reduzindo não apenas a taxa de inflação, mas também o próprio processo de crescimento.

\subsection{INVESTIMENTO}

Os efeitos da elevação dos juros sobre os investimentos se dão de três formas: 1) pelo aumento do custo do financiamento do investimento voltado à produção de bens e serviços; 2) pela redução da atratividade dos investimentos produtivos em relação ao investimento financeiro; 3) pelo impacto sobre as expectativas de crescimento futuro da economia brasileira e do valor do capital.

A redução da taxa de juros para pessoa jurídica, principalmente a partir de meados de 2005 (Gráfico 2), tem permitido uma retomada do investimento produtivo. Após algumas oscilações, a Formação Bruta de Capital Físico (FBKF) começou a mostrar algum fôlego a partir do primeiro trimestre de 2006 (destacado no Gráfico 5 - quadrado maior), apresentado taxas positivas em todos os trimestres a parir de então.

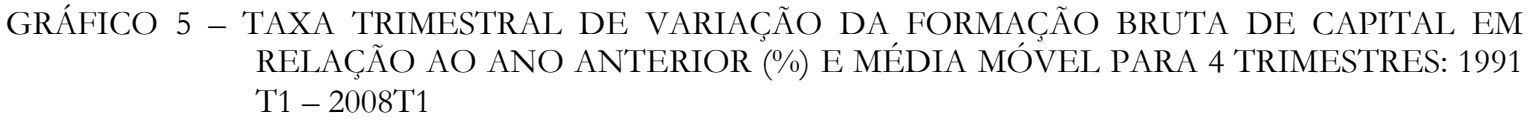
RELAÇÃO AO ANO ANTERIOR (\%) E MÉDIA MÓVEL PARA 4 TRIMESTRES: 1991 $\mathrm{T} 1-2008 \mathrm{~T} 1$

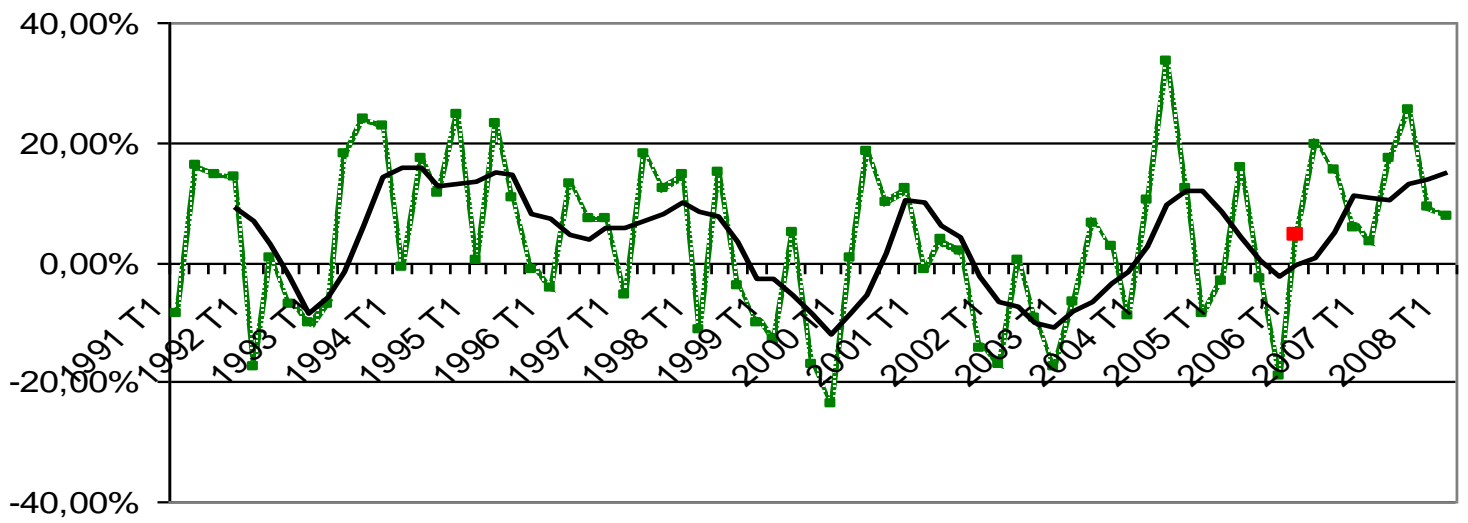

tavouna de variação FBKF 4 pód. Móv. (taxa de variação FBKF)

FONTE: Instituto Brasileiro de Geografia e Estatística (IBGE/SCN).

Certamente, a redução dos juros das operações de crédito destinadas às pessoas jurídicas tem um impacto positivo nos investimentos sobre a economia pela redução dos custos de captação. Por outro lado, a redução da taxa básica de juros (Selic), conforme apresentado no Gráfico 6, afeta a atratividade do investimento financeiro de maior segurança, incentivando o investimento produtivo. 
GRÁFICO 6 - TAXA BÁSICA DE JUROS (SELIC) REAL E NOMINAL - 04/2001 - 05/2008

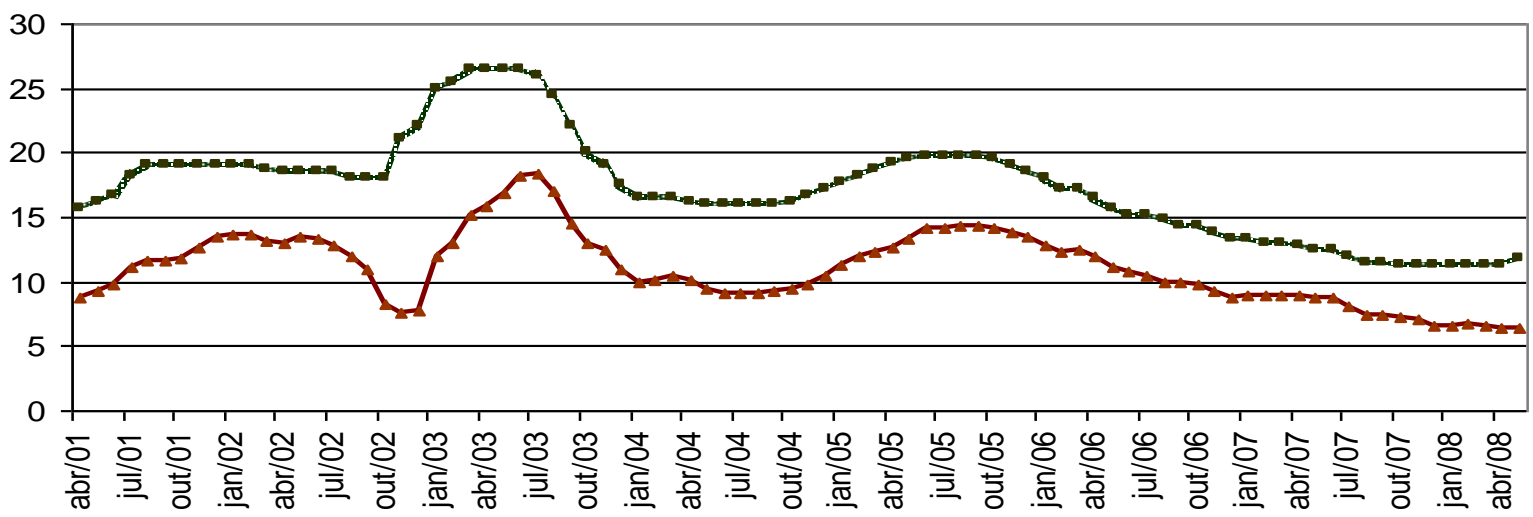

- Juros Reais (ex-ante) COPOM

FONTE: Elaboração própria a partir de dados do Boletim do Banco Central do Brasil.

No entanto, é importante ressaltar que o aumento da taxa básica de juros ainda não é suficiente para compensar o aumento das expectativas de aumento da inflação, ocorrendo, desse modo, uma redução da taxa de juros reais até maio de 2008, conforme apresentado no Gráfico 6.

Finalmente, considerando as expectativas dos agentes, há uma percepção de que os juros nominais continuarão em um processo de elevação com impactos sobre a redução da demanda e da inflação, ou seja, as expectativas em relação ao nível da taxa de juros real é de alta.

Desse modo, a recente mudança na trajetória da taxa de juros nominal tem impactos sobre as expectativas futuras das taxas reais de juros. Os efeitos são de uma redução no valor do capital, pois este é composto pelos fluxos futuros esperados de seus rendimentos descontados pela taxa de juros esperada. Considerando que não ocorram variações no preço do capital, esse efeito leva a uma queda do nível de investimentos.

Além disso, a redução do consumo realizado através de financiamento e o efeito sobre as expectativas dos agentes em relação à queda da renda permanente favorecem uma redução das vendas e, conseqüentemente, do retorno do capital, com efeitos negativos sobre os investimentos.

Como visto anteriormente, os efeitos da redução da demanda favorecem a queda da inflação no curto prazo. No entanto, as implicações de uma elevação da taxa real de juros sobre o nível de investimentos é crucial na determinação do equilíbrio interno da economia brasileira na medida em que reduz a capacidade de crescimento econômico futuro sem pressões inflacionárias. 


\subsection{FLUXO DE CAPITAIS E TAXA DE CÂMBIO}

Altas taxas de juros também levam a uma apreciação da taxa de câmbio com impactos negativos sobre o saldo da balança comercial ao estimular as importações e desestimular as exportações, o que eleva a vulnerabilidade externa da economia, além de provocar uma mudança em sua estrutura produtiva.

Alguns analistas afirmam que se o câmbio está apreciando é porque há um excesso de divisas na economia brasileira e que o próprio processo de apreciação a levará para o equilíbrio com uma redução do superávit comercial.

No entanto, essa análise é superficial visto que não considera as diferentes fontes de divisas e que a manutenção de um câmbio apreciado por um longo período de tempo leva a algumas mudanças da estrutura produtiva com efeitos sobre o crescimento em prazos mais longos de tempo.

Aprofundando um pouco a análise, pelo Gráfico 7, podemos observar que 0 crescimento das exportações brasileiras se deve, principalmente, à elevação em seu nível de preços. Esse efeito poderia ser devido a uma elevação das exportações de bens de maior valor agregado.

\section{GRÁFICO 7 - EVOLUÇÃO DAS EXPORTAÇÕES BRASILEIRAS: EIXO ESQUERDO US\$ F.O.B.} (BILHÕES); EIXO DIREITO KG LÍQUIDO (BILHÕES)

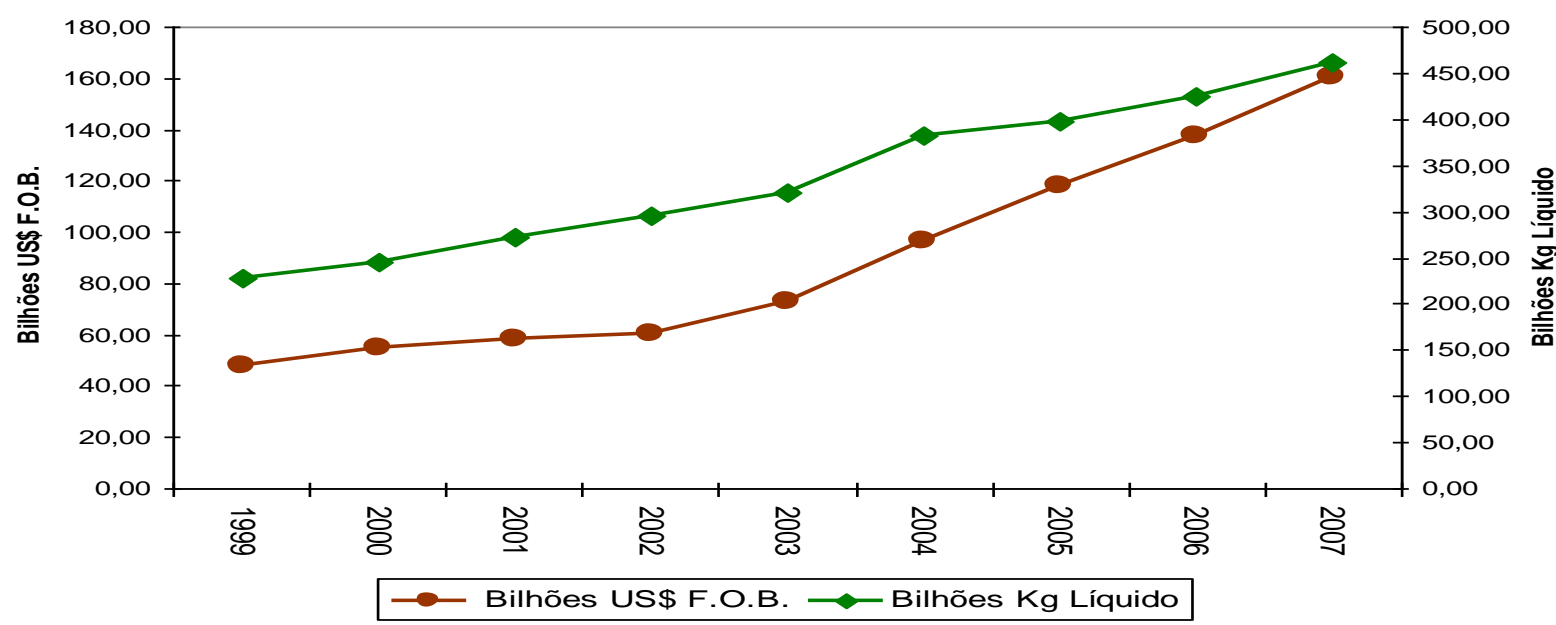

FONTE: Elaboração própria a partir do SECEX/MDIC.

No entanto, esse não é o caso, pois no período 1999-2007 o movimento é o inverso: ganhos de participação na pauta de exportação dos produtos básicos em detrimento dos manufaturados, como se pode constatar pelo Gráfico 8. 
GRÁFICO 8 - EVOLUÇÃO DAS EXPORTAÇÕES BRASILEIRAS POR FATOR AGREGADO

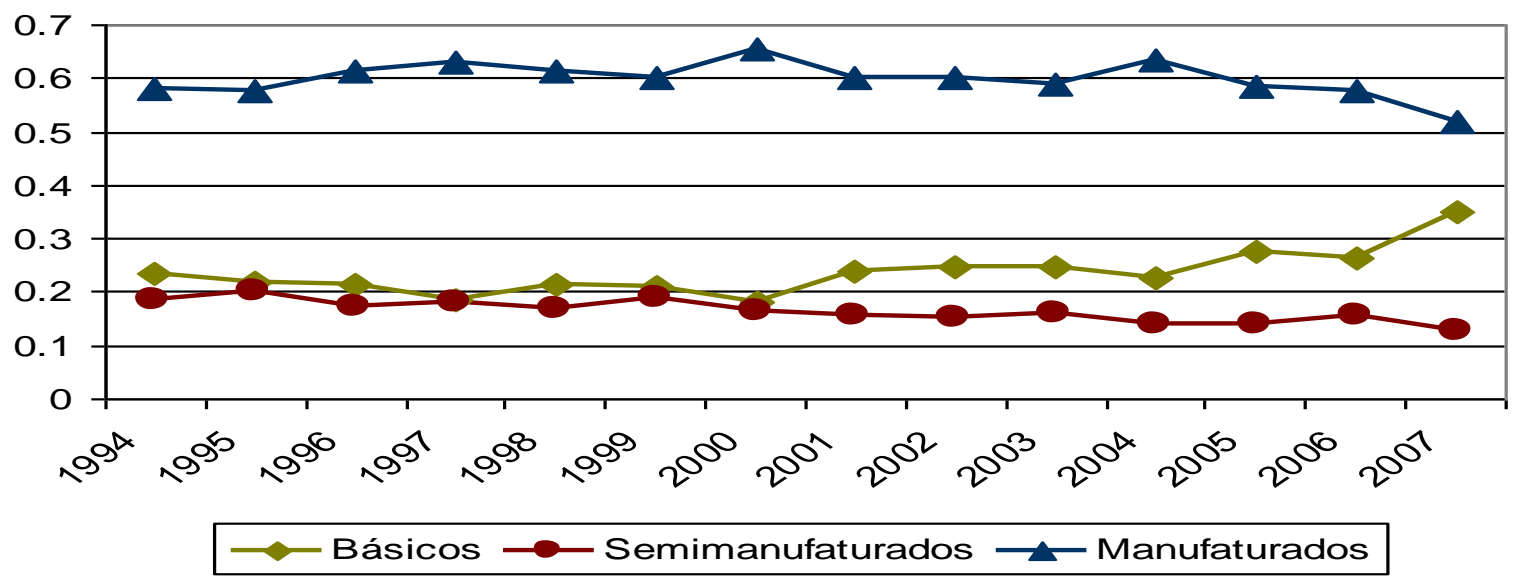

FONTE: Elaboração própria a partir dos dados do SECEX/MDIC.

Assim, os dados confirmam que o grande impulso nas exportações brasileiras nos anos recentes se deve ao aumento da demanda mundial por commodities agrícolas e bens industriais básicos, com efeitos sobre o preço de equilíbrio dos mesmos.

O problema desse processo é o aumento da dependência da base exportadora em bens que são menos dinâmicos tecnologicamente, o que prejudica o desempenho exportador tanto no médio quanto no longo prazo. Porcille e Pereira (2008) mostram que apesar do Brasil manter um superávit com a China, as exportações brasileiras com destino a esse país são, cada vez mais, baseadas em produtos primários. Por outro lado, as importações brasileiras provenientes da China são de produtos de alta tecnologia. Esse tipo de inserção no comércio internacional leva os autores a alertarem para o dinamismo futuro das exportações brasileiras em relação às suas importações.

Jayme e Resende (2008) ainda chamam a atenção para o problema do ajuste estrutural em conta corrente, ou seja, a mudança necessária para superar a restrição externa está longe de ocorrer. Os autores também mostram que o país não apresenta uma inserção internacional competitiva nas categorias de alta e média intensidade tecnológica. Os autores concluem que:

... uma maior inserção em produtos com maior intensidade tecnológica é o que pode vir a garantir a possibilidade de crescimento de longo prazo não constrangido pelo balanço de pagamentos. Vale dizer, na incapacidade de fazer o catching up, países como o Brasil - com um padrão de especialização no comércio exterior essencialmente voltado para commodities primárias, bens de baixa intensidade tecnológica e bens intensivos em recursos naturais e mão-de-obra - dependem, em última instância, de condições favoráveis na demanda externa para manter um crescimento sustentado livre de crises externas (p. 11).

Uma taxa de câmbio mais competitiva está longe de ser uma panacéia, mas é um dos fatores relevantes para estimular setores chaves da economia. Uma taxa de juros mais elevada 
está somente levando a uma especialização em setores menos dinâmicos tecnologicamente que ainda poderá gerar maiores problemas de restrição externa futuramente.

\subsection{DÍVIDA PÚBLICA}

Finalmente, quanto mais elevado o nível dos juros, maior o valor pago pelo governo federal para um dado nível da dívida pública, o que pressiona ainda mais o nível dos seus gastos com pagamentos de juros.

A dívida pública teve um aumento significativo a partir do início de 1998, de acordo com os dados apresentados no Gráfico 9. Como citado anteriormente, um dos fatores que influenciou o crescimento da dívida foi a própria elevação da taxa de juros dos títulos públicos, sendo este um importante instrumento utilizado para conter fuga de capitais em períodos de crise nos anos 90 e começo dos anos 2000.

GRÁFICO 9 - EVOLUÇÃO DA DÍVIDA LÍQUIDA TOTAL DO SETOR PÚBLICO (\% DO PIB): $01 / 2001$ A 04/2008

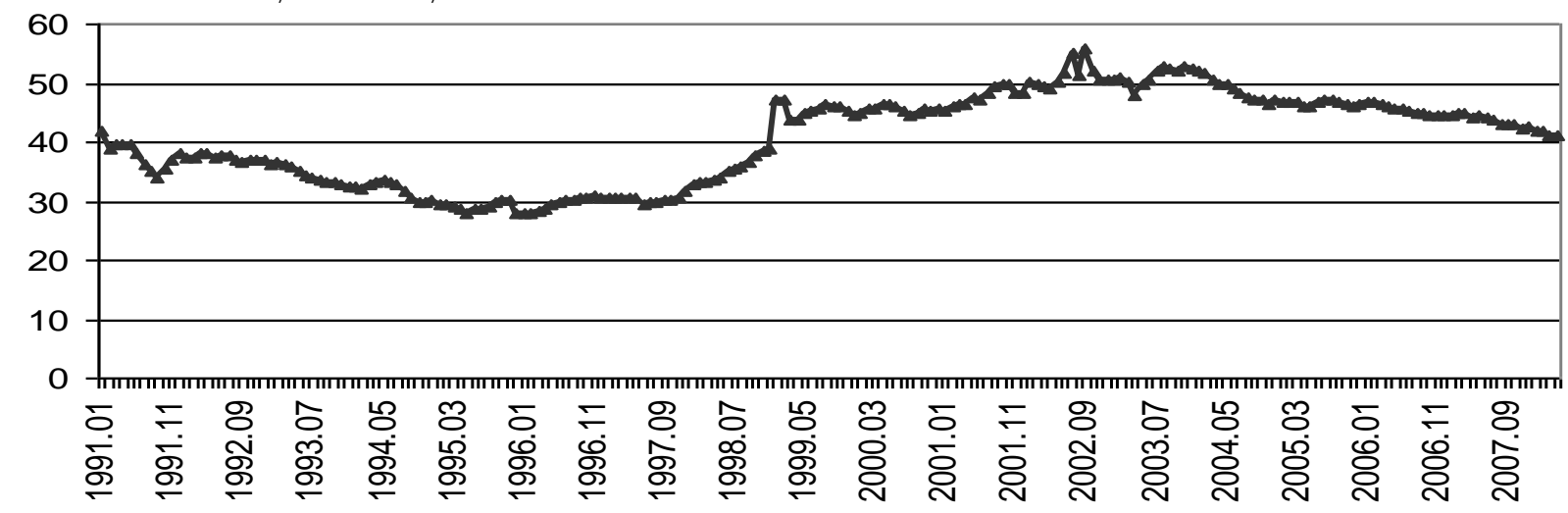

- Dívida total do setor público - líquida - (\% PIB)

FONTE: Elaboração própria a partir de dados do Boletim do Banco Central do Brasil.

Os efeitos dos juros ficam mais claros com os dados apresentados no Gráfico 10 (próxima página). 


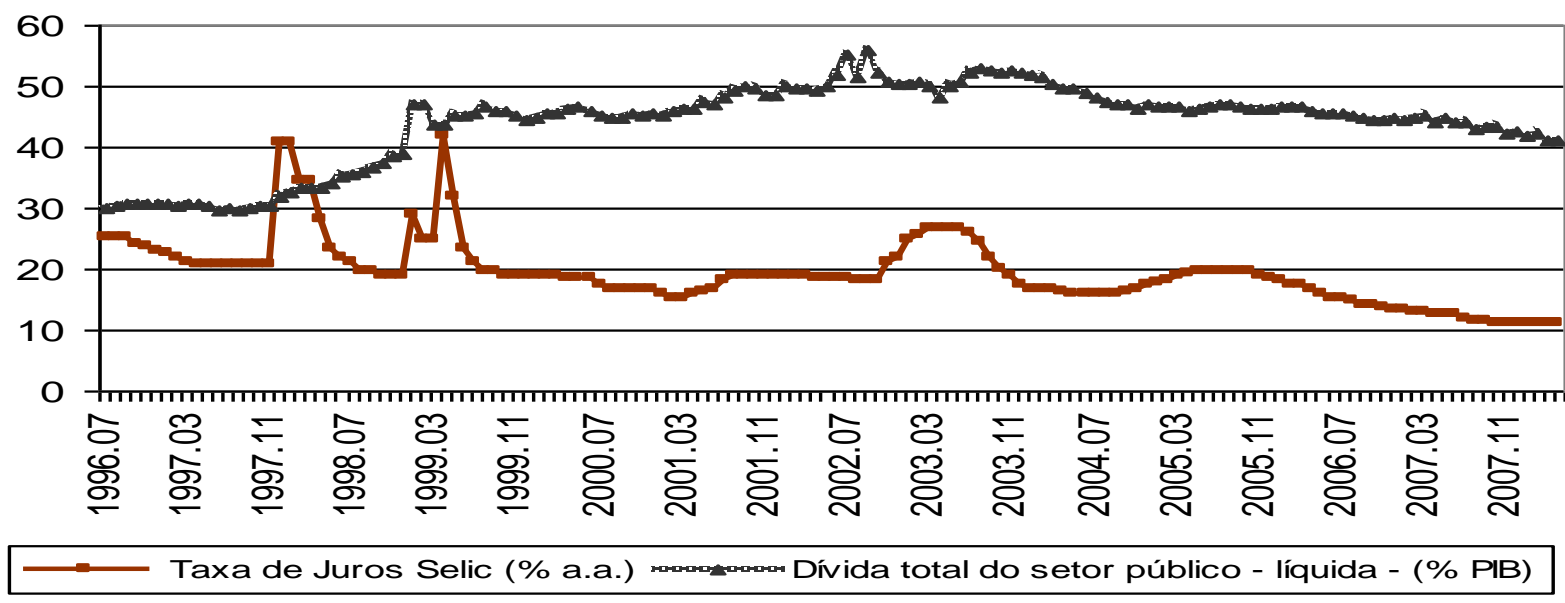

FONTE: Elaboração própria a partir de dados do Boletim do Banco Central do Brasil.

Percebe-se, pelo Gráfico 10 que a dívida pública líquida total do setor público começou a se elevar com os grandes aumentos das taxas nominais de juros, em 1997/1998 e 1999, para conter a fuga de capitais com as crises dos países asiáticos, da Rússia, da Argentina e do próprio Brasil. A taxa nominal de juros ultrapassou a faixa de $40 \%$ em dezembro de 1997 e janeiro de 1998 e chegou a 42\%, em abril de 1999.

Nota-se ainda, pelos dados apresentados no Gráfico 10, que a dívida interna continuou a se elevar mesmo com a redução da taxa de juros. Entre outros fatores, a depreciação do real teve um papel importante na medida em que boa parte da dívida pública estava atrelada ao câmbio. A partir de 2003, ocorreu uma queda da dívida pública paralelamente à redução da taxa nominal de juros.

\section{INFLAÇÃO E TAXA DE JUROS}

Outro ponto relevante que merece destaque é que apesar de a taxa de juros ser o principal instrumento de combate à inflação no curto prazo, existem evidências que esse instrumento possa ser mais prejudicial do que o normal na atual conjuntura da economia brasileira. $\mathrm{O}$ argumento central é que, embora existam pressões de demanda relevantes, as causas centrais do processo inflacionário encontram-se nas elevações dos preços dos alimentos, fenômeno mundial e intimamente ligado ao choque do petróleo e ao crescimento na demanda por alimentos nos países emergentes, com destaque para China e Índia. Trata-se, portanto, de um clássico choque de oferta adverso.

A Tabela 1 apresenta o comportamento dos preços de alguns setores/produtos selecionados e que compõe o IPCA 
TABELA 1 - IPCA - ITENS SELECIONADOS - ACUMULADO ABRIL DE 2007-ABRIL DE 2008

\begin{tabular}{|c|c|}
\hline IPCA & 5,04 \\
\hline 1.Alimentação e bebidas & 12,62 \\
\hline 1101051.Feijão - mulatinho & 159,33 \\
\hline 1101052.Feijão - preto & 125,47 \\
\hline 1102012.Farinha de trigo & 25,44 \\
\hline 1103043.Cebola & 56,86 \\
\hline 1107.Carnes & 24,49 \\
\hline 1111.Leites e derivados & 17,80 \\
\hline 1112.Panificados & 16,90 \\
\hline 1112015.Pão francês & 23,11 \\
\hline 1113013.Óleo de soja & 58,30 \\
\hline 3201.Eletrodomésticos e equipamentos & $-2,35$ \\
\hline 3201001.Refrigerador & $-1,74$ \\
\hline 3201002.Condicionador de ar & $-4,07$ \\
\hline 3201003.Máquina de costura & 2,24 \\
\hline 3201006.Máquina de lavar roupa & $-6,03$ \\
\hline 3201012.Liquidificador & 2,83 \\
\hline 3201013.Ventilador & 2,26 \\
\hline 3201021.Fogão & $-0,01$ \\
\hline 3201065.Forno de microondas & $-8,97$ \\
\hline 3202.TV, som e informática & $-10,87$ \\
\hline 3202001.Televisor & $-12,63$ \\
\hline 3202003.Aparelho de som & $-4,44$ \\
\hline 3202005.Aparelho de DVD & $-20,24$ \\
\hline 3202028.Microcomputador & $-12,78$ \\
\hline 33.Consertos e manutenção & $-1,15$ \\
\hline 3301.Consertos e manutenção & $-1,15$ \\
\hline 3301002. Conserto de refrigerador e freezer & $-3,22$ \\
\hline 3301006.Conserto de televisor & $-1,27$ \\
\hline 3301009.Conserto de aparelho de som & $-2,21$ \\
\hline
\end{tabular}

FONTE: IBGE.

Setores em que poderia se esperar a ocorrência de uma inflação de demanda interna, tais como o de eletrodomésticos e equipamentos, pressionados pela expansão do crédito, tem registrado deflação nos últimos meses, fruto da valorização cambial e dos avanços 
tecnológicos da indústria. Por outro, apresenta-se com clareza uma significativa pressão inflacionária derivada da elevação dos preços dos alimentos.

Assim, a pergunta inequívoca é: qual a eficácia da política monetária em controlar este tipo choque? A literatura econômica aponta no sentido de um arrefecimento do efeito recessivo do choque de oferta, tal como apresentado na Figura 1:

FIGURA 1 - CHOQUE DE OFERTA ADVERSO COM POLÍTICA DE RESTRIÇÃO DE DEMANDA

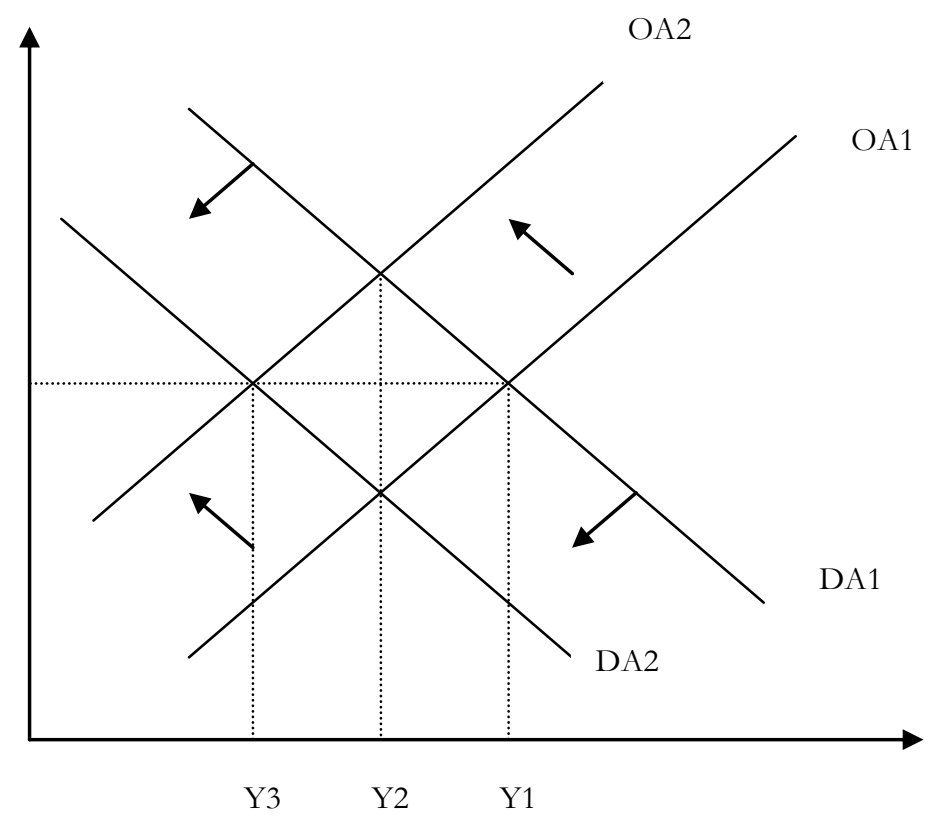

FONTE: Elaboração própria.

A contração monetária e seu efeito recessivo sobre a demanda e, portanto, sobre o nível de atividade tende a acirrar o efeito de recessivo derivado do choque de oferta. $\mathrm{Na}$ prática, caso a política monetária siga a trajetória esperada pode-se prever uma redução do nível na taxa de crescimento da economia brasileira para 2009 superior aquela derivada dos efeitos recessivos do choque de oferta, dando assim continuidade ao processo de stop and go que caracteriza o ritmo de expansão do produto nos últimos vinte e cinco anos.

\section{CONCLUSÕES}

O problema da elevação da taxa de juros (principalmente quanto se parte de patamares elevados) como instrumento de controle da inflação acaba por gerar um círculo vicioso, pois a mesma provoca uma tendência de crescimento da dívida pública que, por sua vez, cria maiores pressões para mantê-la em patamares ainda mais altos, além de seus impactos sobre a redução dos investimentos produtivos que, ao reduzir a oferta, causa pressões inflacionárias no médio prazo. 
Adicionalmente, a contração monetária e seu efeito recessivo sobre a demanda e, portanto, sobre o nível de atividade tende a acirrar o efeito de recessivo derivado do choque de oferta. Esses dois efeitos combinados podem reduzir a taxa de crescimento da economia brasileira já em 2009, o que daria continuidade ao processo de crescimento stop and go que caracteriza o ritmo de crescimento da economia desde o começo dos anos 80 .

Desse modo, para compensar a elevação da demanda mundial, o Banco Central está reduzindo a demanda interna e o crescimento da economia brasileira, além de mantê-la em um circulo vicioso de baixo crescimento. Em outras palavras, estamos pagando pela negligência de outros países com o controle de suas respectivas taxas de inflação. Talvez fosse o momento de agir de forma similar e acomodar uma inflação mais alta que não tem raiz na economia brasileira e, desse modo, é passageira.

\section{REFERÊNCIAS}

PORCILE, G.; PEREIRA, W. (2008). A ascensão da China na economia mundial: efeitos sobre o Brasil e a America Latina. Economia \& Tecnologia, UFPR, v.12, p.19-28, 2008.

JAYME JR, F.G. E RESENDE, M.C. (2008). Restrição externa ao crescimento: evidências recentes no Brasil. Economia \& Tecnologia, UFPR, v.12, p.5-17, 2008. 
